\title{
Validation of the adult attention-deficit/hyperactivity disorder quality-of-life scale in European patients: comparison with patients from the USA
}

\author{
Meryl Brod • Lenard A. Adler · Sarah Lipsius • \\ Yoko Tanaka $\cdot$ Alexandra N. Heinloth • \\ Himanshu Upadhyaya
}

Received: 21 May 2014/Accepted: 3 December 2014/Published online: 7 January 2015

(C) The Author(s) 2015. This article is published with open access at Springerlink.com

\begin{abstract}
The adult attention-deficit/hyperactivity disorder (ADHD) quality-of-life (AAQoL) scale was previously validated in adult patients in the USA; here, the AAQoL is validated in adult European patients. Data from a 12-week open-label acute treatment period with atomoxetine (80-100 mg/day) in adults with ADHD were used. Patients ( $\geq 18$ to $\leq 50$ years old) had a score $\geq 2$ on $\geq 6$ items on the inattentive or hyperactive core subscales of Conners' Adult ADHD Rating Scale-Investigator Rated: Screening Version (CAARS-Inv:SV); a CAARS-Inv:SV 18-item total ADHD symptom score $\geq 20$; and Conners' Adult ADHD Rating Scale-Observer: Screening Version 6-item inattentive or hyperactive core subscale scores $\geq 2$. Data were stratified based on patients' geographic region (Europe vs USA). Scale validation psychometric properties results were very similar between European $(n=1,217 ; 57.7 \%$ male; mean
\end{abstract}

The study was registered at: http://clinicaltrials.gov/ct2/home under NCT00700427: A Long Term Study of a Medication for Adults With attention-deficit/hyperactivity disorder (ADHD); study code: B4Z-MCLYDO.

Electronic supplementary material The online version of this article (doi:10.1007/s12402-014-0160-z) contains supplementary material, which is available to authorized users.

M. Brod

The Brod Group, Mill Valley, CA, USA

L. A. Adler

New York University School of Medicine, New York, NY, USA

S. Lipsius - A. N. Heinloth

inVentiv Health Clinical, LLC, Ann Arbor, MI, USA

Y. Tanaka $\cdot$ H. Upadhyaya $(\square)$

Eli Lilly and Company, Indianapolis, IN, USA

e-mail: Upadhyaya_himanshu_p@lilly.com age 33.0 years) and US ( $n=602 ; 62.1 \%$ male; mean age 33.5 years) patients, including factor loading, internal consistency, convergent and discriminant validity, and responsiveness. Exploratory factor analysis confirmed four AAQoL subscales. Internal consistency was acceptable (Cronbach's alpha $>0.70$ for all subscales). The AAQoL total score showed moderate convergent validity with CAARS-Inv:SV 18-item total ADHD symptom and clinical global impression-ADHD-severity (CGI-ADHD-S) scores; and strong convergent validity with Behavior Rating Inventory of Executive Function-Adult Version: SelfReport Global-Executive-Composite Index scores. Mean AAQoL total scores were significantly different among patients grouped by CGI-ADHD-S scores, suggesting good discriminant validity. The AAQoL total and subscale scores presented good responsiveness from baseline to 12 weeks. The AAQoL scale shows comparable validity in European and US adults with ADHD.

Keywords Atomoxetine - Exploratory factor analysis . Convergent validity $\cdot$ Discriminate validity .

Responsiveness

\section{Background}

Effects of attention-deficit/hyperactivity disorder (ADHD) in adults go beyond symptoms of inattention, hyperactivity, and impulsivity that characterize the disorder (Adler et al. 2008; Matza et al. 2011). The impact of ADHD involves many aspects of the patient's life, such as lack of organization, difficulty concentrating, forgetfulness, greater employment disruption, lower academic achievement, difficulty initiating and maintaining relationships, and poor driving behaviors (Adler et al. 2008). It has been shown 
that ADHD is associated with increased psychological dysfunction and disability, significant job impairment, drug and alcohol misuse, family conflicts, violence, traffic violations, and accidents (Adler et al. 2009). Not surprisingly, patients with ADHD report lower quality-of-life (QoL) than healthy comparison subjects, and the severity of ADHD symptoms is negatively correlated with measures of QoL (Adler et al. 2009; Mattos et al. 2012). Moreover, at least in children with ADHD, the overall impact of the disease is comparable to other major psychiatric disorders or to severe physical conditions (Biederman et al. 2006a; Danckaerts et al. 2010).

The adult ADHD quality-of-life (AAQoL) scale assesses QoL in adult patients with ADHD (Brod et al. 2006). It was developed based on qualitative data on the impact of ADHD on everyday activities as reported by patients and experts, as well as information collected from the scientific literature (Mattos et al. 2011). The AAQoL scale development followed the industry guidance "Patient-Reported Outcome Measures: Use in Medical Product Development to Support Labeling Claims" set by the Food and Drug Administration (http://www.fda.gov/downloads/Drugs/Gui danceComplianceRegulatoryInformation/Guidances/UCM 193282.pdf.). In 2006, the AAQoL was first validated in a retrospective cohort study conducted in the USA that included adult patients with ADHD $(n=989)$ treated with atomoxetine. Psychometric validation results showed the ability of the AAQoL to quantify the QoL consequences of ADHD (Brod et al. 2006).

While the AAQoL has been validated and successfully used in adult US patients with ADHD, validation data in European patients are lacking. Here, we examine the validity of the AAQoL in adult European patients with ADHD treated with atomoxetine. We compare our results with data from adult US patients with ADHD treated with atomoxetine who participated in the same clinical trial.

\section{Methods}

This manuscript presents the results of secondary analyses of clinical trial data from an open-label treatment period, focusing on the validation of the AAQoL as a measurement scale in adult European patients with ADHD. The results of the primary study objective, examining the maintenance of response to atomoxetine compared with placebo in adult patients with ADHD, were published elsewhere (Upadhyaya et al. 2013a, b).

\section{Study design}

Data were used from a Phase 3, randomized, double-blind maintenance-of-response trial of atomoxetine $(80-100 \mathrm{mg} /$ day) versus placebo in adult outpatients with ADHD. Data were used from the open-label treatment phase of the study, during which all enrolled patients received treatment with atomoxetine (starting dose: $40 \mathrm{mg} /$ day; target dose: 80 or $100 \mathrm{mg} /$ day) for 12 weeks. The study was conducted in 152 centers across 18 countries. For the current analyses, only data collected during the 12-week open-label treatment period in 50 centers in the US and in 82 centers in European countries were used. European countries included Austria, Belgium, Denmark, Finland, France, Germany, Italy, the Netherlands, Portugal, Spain, Sweden, Switzerland, and the UK. Data from additional non-European study centers located in Argentina, Canada, Mexico, and Russia were not included in the present analyses.

\section{Patients}

Adults ( $\geq 18$ to $\leq 50$ years old) of either gender with a current and historical diagnosis of ADHD, as defined by Diagnostic and Statistical Manual of Mental Disorders, Fourth Edition, Text Revision ${ }^{T M}$ (DSM-IV-TR ${ }^{\mathrm{TM}}$ ) criteria and a score of $\geq 2$ on at least 6 items of either the inattentive or hyperactive core subscales of the Conners' Adult ADHD Rating Scale-Investigator Rated: Screening Version (CAARS-Inv:SV) with adult ADHD prompts, were enrolled. In addition, patients had a CAARS-Inv:SV total ADHD symptom score of $\geq 20$, a score of $\geq 2$ on at least 6 items of either the inattentive or hyperactive core subscales of conners' adult attention-deficit/hyperactivity disorder rating scale-observer: screening version (CAARS-O:SV), and a score of $\geq 4$ on the CGI-ADHD-S. Excluded were patients who met full DSM-IV-TR diagnostic criteria for any history of bipolar disorder, current major depression, a current anxiety disorder (including generalized anxiety disorder, panic disorder, or social phobia), or any history of a psychotic disorder (confirmed by the structured interview); patients with HAMD-17 or HAMA scores of $\geq 15$; and patients with organic brain disease.

\section{Rating scales}

In the current analyses, four different rating scales assessing disease severity were included-the AAQoL, the CAARS-Inv:SV total ADHD symptom scale, the CGI-ADHD$\mathrm{S}$ scale, and the Behavior Rating Inventory of Executive Function-Adult Version: Self-Report (BRIEF-A) scale. All scales were translated using well-recognized scientific guidelines for translation of patient-reported outcome measures (Lohr et al. 1996) and administered in 11 different languages (Danish, Dutch, English, Finnish, French, German, Italian, Portuguese, Russian, Spanish, and Swedish), with the language of the scale depending on the prevalent language(s) of the patients' country of residence. 
The AAQoL is a 29-item questionnaire designed to assess QoL and was a secondary efficacy measure in this trial (access information: www.thebrodgroup.net). It includes four domains (subscale scores): (1) Life Productivity (11 items), including "getting things done on time," "completing projects or tasks," "remembering important things," and "balancing multiple projects;" (2) Psychological Health (6 items), including "feeling anxious," "overwhelmed," and "fatigued;" (3) Relationships (5 items), including "tension," "annoyance," and "frustration in relationships;" (4) Life Outlook (7 items), including "perceptions that energy is well spent," "people enjoy spending time with you," "you can successfully manage your life," and "you are as productive as you would like to be." Each item is rated by patients on a 5-point Likert scale ranging from "Not at all/Never" (1) to "Extremely/Very Often" (5). To derive overall and subscale scores, item scores are transformed to a 0-100-point scale. Then, the item scores are summed up and divided by item count to generate subscale and overall scores. If $>1$ item of a subscore was missing, the subscore was treated as missing. If $>3$ items for the overall score were missing, the overall score was treated as missing (HCP Team: http://www. hcplive.com/publications/DIALOGS-ADHD/2007/Jun2007/ Dialogs_ADHD_Quality_of_Life.). A higher score indicates greater QoL (Brod et al. 2006).

The CAARS-Inv:SV total ADHD symptom scale and the CGI-ADHD-S scale were used as primary efficacy measures in this trial. The CAARS-Inv:SV total ADHD symptom scale consists of the Inattention and Hyperactivity/Impulsivity subscales of the CAARS-Inv:SV. The CAARS-Inv:SV is a 30 -item scale containing three subscales: the Inattention subscale (items 1, 9, 13, 14, 19, 21, 26, 29, and 30), the Hyperactivity/Impulsivity subscale (items 2, 4, 6, 8, 16, 18, 22, 25, and 27), and the ADHD Index (items 3, 5, 7, 10, 11, 12, 15, 17, 20, 23, 24, and 28) (Conners et al. 1999). Each item on the CAARS-Inv:SV assesses symptom severity over the previous week and is scored on a $0-3$ scale $(0=$ not at all, never; $1=$ just a little, once in a while; $2=$ pretty much, often; $3=$ very much, very frequently). Adult ADHD prompts were embedded into the 18 items for the total ADHD symptom score (Upadhyaya et al. 2013a). An ADHD symptom was considered to be present if the score on the corresponding item was $\geq 2$. The scale was scored by qualified raters based on interviews with the patients.

The CGI-ADHD-S is a single-item scale. It is rated based on the clinician's assessment of the overall severity of the patient's ADHD in relation to the clinician's total experience (National Institute of Mental Health 1985; Guy 1976). Severity is rated on a 7 -point scale $(1=$ normal or not at all ill; $2=$ borderline mentally ill; $3=$ mildly ill;
$4=$ moderately ill; $5=$ markedly ill; $6=$ severely ill; $7=$ extremely ill).

The BRIEF-A was a secondary efficacy measure in this trial. The BRIEF-A is a standardized self-report measure that captures adults' views of their own executive functions, or self-regulation, in their everyday environments (Roth et al. 2005). It is comprised of 75 equivalent items within nine non-overlapping theoretically and empirically derived clinical scales that measure different aspects of executive functioning: inhibit, shift, emotional control, self-monitor, initiate, working memory, plan/organize, task monitor, and organization of materials. The individual clinical scales form two broader indices: Behavioral Regulation Index and Metacognition Index. These indices form the overall summary score, the Global-Executive-Composite (GEC) Index.

\section{Statistical analyses}

Data from all European and US patients who enrolled in the 12-week open-label treatment phase were included in the analyses. Data were analyzed in three groups: European patient group, US patient group, as well as both groups combined. To analyze the data, statistical software SAS $^{\circledR}$ version 9.1.3 (Cary, NC) was used.

\section{Exploratory factor analysis}

An exploratory factor analysis was used to examine the underlying constructs of the AAQoL in the European patient group and the US patient group. The number of factors (4) examined in the analysis was based upon the known number of AAQoL subscales, and a value of $\geq 0.30$ was deemed to indicate successful factor loading (Cronbach 1951). Principal-components analysis with varimax rotation was used to estimate the factor loadings and, in turn, determine the underlying factor structure of this study's AAQoL items in European and US patient groups (Reid 1995).

\section{Internal consistency}

The degree to which each item of a rating scale co-varies is captured by measures of internal consistency. Internal consistency for the AAQoL total and subscale scores was assessed at baseline and week 12 by use of Cronbach's alpha $(\alpha)$, a measure of the average correlation of items within a scale (Cronbach 1951). Cronbach's $\alpha$ ranges from 0 to 1 , with higher scores indicating greater internal consistency. A commonly accepted minimal standard for internal consistency is a Cronbach's $\alpha$ of 0.65 (Zhang et al. 2005). When comparing groups, Cronbach's $\alpha$ values of 
$0.70-0.80$ are regarded as satisfactory (Bland and Altman 1997).

\section{Convergent validity}

Convergent validity estimates the degree to which any two measures that assess the same or similar entities are related to each other (Stratford et al. 1996). Convergent validity between AAQoL total score and CAARS-Inv:SV total ADHD symptom score, CGI-ADHD-S score, and BRIEFA GEC Index score was assessed at week 12 using Pearson correlation coefficients. In an exploratory analysis, Pearson correlation coefficients of AAQoL subscale scores versus AAQoL total scores, CAARS-Inv:SV, hyperactive/impulsive and inattentive scores, CGI-ADHD-S score, and BRIEF-A Metacognition, Behavioral Regulation, and GEC Index scores at week 12 were determined. Week 12 was the last non-missing value during the 12-week open-label acute treatment period.

Convergent validity was assessed with Pearson correlation coefficients. In the current analyses, correlations with a coefficient value $\leq 0.5$ were classified as weak; those with a correlation coefficient of $>0.5$ but $<0.8$ as moderate; and those with a correlation coefficient of $\geq 0.8$ as strong.

\section{Discriminant validity}

Discriminant validity indicates the ability to discriminate between dissimilar constructs (Stratford et al. 1996) - here, the ability of a scale to discriminate between patient groups with differences in their QoL was assessed. A measure for QoL in patients with ADHD should distinguish between patients with different levels of QoL. Here, comparisons of AAQoL total scores between patients grouped by CGIADHD-S scores at 12 weeks, indicating severity of the disease, were performed. Mean AAQoL total scores were compared between patients with CGI-ADHD-S scores of 1 (normal) versus patients with CGI-ADHD-S scores of 2 through 5 (borderline mentally ill up to markedly ill; $5=$ highest CGI-ADHD-S score at week 12 with a sufficient number of affected patients to produce statistically meaningful results). An analysis of variance was conducted using AAQoL total score as the outcome and CGI-ADHD$\mathrm{S}$ as the predictor; $P$ values were obtained by pairwise comparison.

\section{Responsiveness}

Responsiveness is the extent to which a health status measure accurately reflects change in a patient's condition over time (Matza et al. 2007). The standardized response mean (SRM) is a unitless statistic summarizing responsiveness, defined as the mean change from baseline score divided by the standard deviation of the change scores (Biederman et al. 2006b), similar in concept to effect sizes, but using only data from one treatment group. Wilcoxon signed-rank tests were used to assess withingroup changes from baseline to week 12 for the AAQoL total and subscale scores based on clinical assessment of improvement as measured by the CGI-ADHD-S.

\section{Results}

Patient demographics

A total of 1,819 adult patients with ADHD were considered for this analysis. Among them, 1,217 patients resided in European countries and 602 patients lived in the US. Baseline demographic and clinical characteristics are presented in Table 1. Further comparisons of baseline patient characteristics between European and non-European patients were published previously (Upadhyaya et al. 2013a).

\section{Exploratory factor analysis}

Exploratory factor analysis loaded all AAQoL items onto their previously reported subscales (Brod et al. 2006) with the exception of item \#29 (your intimate relationship is going well emotionally), which loaded on the Relationships subscale instead of the Life Outlook subscale. Loading and significance of loading were very similar between European and US patients for all items including item \#29 (Table 2).

\section{Internal consistency}

Cronbach's $\alpha$, a measure of internal consistency, at baseline, was 0.744 for AAQoL total scores in European patients and 0.771 in US patients; at week 12, Cronbach's $\alpha$ was 0.835 in European patients and 0.851 in US patients. The internal consistency score improved from baseline to week 12 in response to treatment with atomoxetine in both European and US patients. For all four AAQoL subscales (Life Productivity, Psychological Health, Life Outlook, and Relationships), Cronbach's $\alpha$ values were $>0.70$ at baseline and week 12, indicating acceptable internal consistency in European and US patients.

Overall, very similar values for Cronbach's $\alpha$ were observed for European and US patients. Internal consistency remained high and acceptable with Cronbach's $\alpha>0.70$ when patients from European and US groups were combined, at both baseline and week 12 (Table 3). 
Table 1 Baseline demographics

European countries include: Austria, Belgium, Denmark, Finland, France, Germany, Italy, the Netherlands, Portugal, Spain, Sweden, Switzerland, and the UK

$A A Q o L$ adult attention-deficit/ hyperactivity disorder qualityof-life, $A D H D$ attention-deficit/ hyperactivity disorder, $B M I$ body mass index; CAARSInv: $S V$ conner's adult attentiondeficit/hyperactivity disorder investigator rated: screening version, $C G I-A D H D-S$ clinical global impression attentiondeficit/hyperactivity disorderseverity, $E C$ European countries, $N$ total number of patients, $n$ number of affected patients, $S D$ standard deviation, US United States

${ }^{\text {a }} P$ values are from $t$ test

b $P$ values are from Fisher's exact test

\begin{tabular}{|c|c|c|c|c|}
\hline Characteristic & $\begin{array}{l}\mathrm{EC} \\
(N=1,217)\end{array}$ & $\begin{array}{l}\text { US } \\
(N=602)\end{array}$ & $\begin{array}{l}\mathrm{EC}+\mathrm{US} \\
(N=1,819)\end{array}$ & $P$ value \\
\hline Age [years, mean (SD)] & $33.0(9.2)$ & $33.5(8.9)$ & $33.2(9.1)$ & $0.29^{\mathrm{a}}$ \\
\hline Race $[n(\%)]$ & & & & $<0.001^{\mathrm{b}}$ \\
\hline Caucasian & 1,192 (97.9) & $486(80.7)$ & $1,678(92.2)$ & \\
\hline African & $5(0.4)$ & $50(8.3)$ & $55(3.0)$ & \\
\hline Hispanic & $9(0.7)$ & $44(7.3)$ & $53(2.9)$ & \\
\hline Native American & $1(0.1)$ & $5(0.8)$ & $6(0.3)$ & \\
\hline East Asian & $3(0.2)$ & $11(1.8)$ & $14(0.8)$ & \\
\hline West Asian (Indian subcontinent) & $7(0.6)$ & $5(0.8)$ & $12(0.7)$ & \\
\hline Not provided & $0(0.0)$ & $1(0.2)$ & $1(0.1)$ & \\
\hline Gender [n (\%)] & & & & $0.08^{\mathrm{b}}$ \\
\hline Male & $702(57.7)$ & $374(62.1)$ & $1,076(59.2)$ & \\
\hline Female & $515(42.3)$ & $228(37.9)$ & $743(40.8)$ & \\
\hline Body weight $[\mathrm{kg}$, mean $(\mathrm{SD})]$ & $76.8(17.6)$ & $84.1(19.3)$ & $79.2(18.5)$ & $<0.001^{\mathrm{a}}$ \\
\hline Height $[\mathrm{cm}$, mean $(\mathrm{SD})]$ & $173.8(9.3)$ & $172.3(10.0)$ & $173.3(9.6)$ & $0.002^{\mathrm{a}}$ \\
\hline BMI $\left[\mathrm{kg} / \mathrm{m}^{2}\right.$, mean $\left.(\mathrm{SD})\right]$ & $25.3(5.0)$ & $28.3(5.9)$ & $26.3(5.5)$ & $<0.001^{\mathrm{a}}$ \\
\hline ADHD subtype [n (\%)] & & & & $<0.001^{\mathrm{b}}$ \\
\hline Inattentive & $298(24.5)$ & $115(19.1)$ & $413(22.7)$ & \\
\hline Hyperactive/impulsive & $40(3.3)$ & $4(0.7)$ & $44(2.4)$ & \\
\hline Combined & 872 (71.7) & $482(80.1)$ & $1,354(74.4)$ & \\
\hline Not applicable & $1(0.1)$ & $0(0.0)$ & $1(0.1)$ & \\
\hline CGI-ADHD-S score [mean (SD)] & $5.1(0.8)$ & $4.6(0.6)$ & $5.0(0.8)$ & $<0.001^{\mathrm{a}}$ \\
\hline \multicolumn{5}{|l|}{ CAARS-Inv:SV score [mean $(S D)]$} \\
\hline $\begin{array}{l}\text { Hyperactivity-Impulsivity subscale } \\
\text { imputed }\end{array}$ & $17.4(5.2)$ & $18.3(4.9)$ & $17.7(5.1)$ & $<0.001^{\mathrm{a}}$ \\
\hline Inattention subscale imputed & $20.9(3.6)$ & $21.6(3.6)$ & $21.1(3.6)$ & $<0.001^{\mathrm{a}}$ \\
\hline Total ADHD symptom imputed & $38.3(6.7)$ & $39.9(6.8)$ & $38.8(6.8)$ & $<0.001^{\mathrm{a}}$ \\
\hline \multicolumn{5}{|l|}{$A A Q o L$ [mean $(S D)]$} \\
\hline Total score imputed & $47.6(14.3)$ & $48.0(14.0)$ & $47.7(14.2)$ & $0.53^{\mathrm{a}}$ \\
\hline Psychological Health section score & $51.4(20.9)$ & $53.1(19.2)$ & $52.0(20.3)$ & $0.09^{\mathrm{a}}$ \\
\hline Relationships section score & $53.6(21.2)$ & $52.8(19.1)$ & $53.3(20.5)$ & $0.44^{\mathrm{a}}$ \\
\hline Life Outlook section score & $45.1(17.0)$ & $52.5(14.9)$ & $47.6(16.7)$ & $<0.001^{\mathrm{a}}$ \\
\hline Life Productivity section score & $44.2(18.1)$ & $40.3(19.0)$ & $42.9(18.5)$ & $<0.001^{\mathrm{a}}$ \\
\hline
\end{tabular}

\section{Convergent validity}

As assessed with Pearson correlation coefficients, at 12 weeks, AAQoL total scores demonstrated moderate convergent validity with CAARS-Inv:SV total ADHD symptom and CGI-ADHD-S scores, in both European and US patient populations. Correlations between AAQoL total scores and BRIEF-A GEC Index scores were strong in both European and US patient populations (Supplemental Table 1).

Overall, European and US patient populations showed very similar correlation values between AAQoL total scores and CAARS-Inv:SV total ADHD symptom scores, CGI-ADHD-S scores, and BRIEF-A GEC Index scores, indicating very similar convergent validity in European and US patient groups (Supplemental Table 1).
In an exploratory analysis, Pearson correlation coefficients between AAQoL subscale scores and AAQoL total scores as well as CAARS-Inv:SV hyperactive/impulsive score, CAARS-Inv:SV inattentive score, CGI-ADHD-S score, BRIEFA Metacognition Index score, BRIEF-A Behavioral Regulation Index score, and BRIEF-A GEC Index score at 12 weeks were assessed (Supplemental Table 1).

All four AAQoL subscale scores had moderate-tostrong correlations with the AAQoL total score in European and US patients. Correlations with the CAARS-Inv:SV hyperactive/impulsive subscale score were weak for all AAQoL subscale scores in European and US patient groups. For the CAARS-Inv:SV inattentive subscale, correlations with AAQoL subscale scores were weak to moderate for European and US patient groups. 
Table 2 Exploratory factor analysis for adult attentiondeficit/hyperactivity disorder quality-of-life scale
European countries include Austria, Belgium, Denmark, Finland, France, Germany, Italy, the Netherlands, Portugal, Spain, Sweden, Switzerland, and the UK

AAQoL Adult attention-deficit/ hyperactivity disorder qualityof-life, EC European countries, $n$ number of patients with a baseline value, US United States

${ }^{\text {a }}$ Item \#29 loaded in our study for European and US groups on the AAQoL Relationships subscale instead of AAQoL Life Outlook subscale. This may be due to the fact that conceptually the item could belong to both Life Outlook and Relationships subscales

\begin{tabular}{|c|c|c|c|c|c|}
\hline \multirow[t]{2}{*}{ Subscale } & \multirow[t]{2}{*}{ Item } & \multirow[t]{2}{*}{ Item description } & \multicolumn{3}{|c|}{ Factor loading } \\
\hline & & & $\begin{array}{l}\mathrm{EC} \\
n=1,137\end{array}$ & $\begin{array}{l}\text { US } \\
n=594\end{array}$ & $\begin{array}{l}\mathrm{EC}+\mathrm{US} \\
n=1,731\end{array}$ \\
\hline \multirow[t]{11}{*}{$\begin{array}{l}\text { Life } \\
\text { productivity }\end{array}$} & 1 & $\begin{array}{l}\text { Keep the house/apartment clean or } \\
\text { uncluttered }\end{array}$ & 0.620 & 0.651 & 0.627 \\
\hline & 2 & $\begin{array}{l}\text { Manage your finances (such as cashing } \\
\text { checks, balancing your checkbook, paying } \\
\text { bills on time) }\end{array}$ & 0.553 & 0.596 & 0.582 \\
\hline & 3 & Remember important things & 0.562 & 0.686 & 0.624 \\
\hline & 4 & $\begin{array}{l}\text { Get your shopping done (such as for food, } \\
\text { clothes, or household items) }\end{array}$ & 0.514 & 0.621 & 0.576 \\
\hline & 5 & Pay attention when interacting with others & 0.417 & 0.588 & 0.507 \\
\hline & 11 & Getting things done requires too much effort & 0.569 & 0.613 & 0.554 \\
\hline & 22 & $\begin{array}{l}\text { Complete projects or tasks (either at work or } \\
\text { at home) }\end{array}$ & 0.758 & 0.721 & 0.739 \\
\hline & 23 & $\begin{array}{l}\text { Get started with tasks you do not find } \\
\text { interesting }\end{array}$ & 0.686 & 0.685 & 0.678 \\
\hline & 24 & Balance multiple projects & 0.647 & 0.672 & 0.661 \\
\hline & 25 & Get things done on time & 0.764 & 0.719 & 0.733 \\
\hline & 26 & $\begin{array}{l}\text { Keep track of important items (such as keys, } \\
\text { wallet) }\end{array}$ & 0.502 & 0.573 & 0.553 \\
\hline \multirow{6}{*}{$\begin{array}{l}\text { Psychological } \\
\text { health }\end{array}$} & 6 & Overwhelmed & 0.463 & 0.634 & 0.518 \\
\hline & 7 & Anxious & 0.725 & 0.741 & 0.731 \\
\hline & 8 & Depressed & 0.700 & 0.728 & 0.721 \\
\hline & 13 & $\begin{array}{l}\text { You have overreacted in difficult or stressful } \\
\text { situations }\end{array}$ & 0.394 & 0.321 & 0.421 \\
\hline & 20 & Feeling fatigued & 0.603 & 0.514 & 0.584 \\
\hline & 21 & $\begin{array}{l}\text { Fluctuations (ups and downs) in your } \\
\text { emotions }\end{array}$ & 0.671 & 0.674 & 0.703 \\
\hline \multirow[t]{7}{*}{ Life outlook } & 14 & $\begin{array}{l}\text { Your energy is well spent (has positive } \\
\text { results) }\end{array}$ & 0.703 & 0.703 & 0.713 \\
\hline & 15 & Able to enjoy time spent with others & 0.644 & 0.550 & 0.618 \\
\hline & 16 & You can successfully manage your life & 0.700 & 0.655 & 0.693 \\
\hline & 17 & As productive as you would like to be & 0.683 & 0.646 & 0.664 \\
\hline & 27 & Good about yourself & 0.666 & 0.633 & 0.678 \\
\hline & 28 & People enjoy spending time with you & 0.521 & 0.597 & 0.541 \\
\hline & $29^{\mathrm{a}}$ & $\begin{array}{l}\text { Your intimate relationship is going well } \\
\text { emotionally }\end{array}$ & 0.155 & 0.018 & 0.091 \\
\hline \multirow[t]{6}{*}{ Relationships } & 9 & $\begin{array}{l}\text { You have not been able to meet others' } \\
\text { expectations of you (either at home or at } \\
\text { work) }\end{array}$ & 0.364 & 0.305 & 0.333 \\
\hline & 10 & You annoyed people & 0.731 & 0.662 & 0.716 \\
\hline & 12 & People are frustrated with you & 0.710 & 0.637 & 0.697 \\
\hline & 18 & Tension in relationships & 0.556 & 0.569 & 0.515 \\
\hline & 19 & Not having quality time to spend with others & 0.391 & 0.566 & 0.394 \\
\hline & $29^{\mathrm{a}}$ & $\begin{array}{l}\text { Your intimate relationship is going well } \\
\text { emotionally }\end{array}$ & -0.306 & -0.268 & -0.306 \\
\hline
\end{tabular}

All AAQoL subscale scores showed weak correlations with the CGI-ADHD-S score with the exception of the Life Productivity subscale, which demonstrated moderate correlation with the CGI-ADHD-S score in both European and US patients. The AAQoL Productivity subscale score was also moderately correlated with both the BRIEF-A Metacognition Index score and the BRIEFA GEC Index score. For the remaining 3 AAQoL subscales, scores were low moderately correlated with the BRIEF-A Metacognition Index score and the BRIEF-A 
Table 3 Internal consistency as represented by AAQoL subscales: Cronbach's Alpha at baseline and week 12

\begin{tabular}{|c|c|c|c|c|c|c|}
\hline \multirow[t]{2}{*}{ Variable category } & \multicolumn{2}{|l|}{$\mathrm{EC}$} & \multicolumn{2}{|l|}{ US } & \multicolumn{2}{|l|}{$\mathrm{EC}+\mathrm{US}$} \\
\hline & Baseline & Week 12 & Baseline & Week 12 & Baseline & Week 12 \\
\hline \multirow[t]{2}{*}{ Life productivity subscale } & 0.854 & 0.920 & 0.881 & 0.929 & 0.864 & 0.923 \\
\hline & $n=1,180$ & $n=1,023$ & $n=600$ & $n=491$ & $n=1,780$ & $n=1,514$ \\
\hline \multirow[t]{2}{*}{ Psychological health subscale } & 0.772 & 0.841 & 0.778 & 0.843 & 0.766 & 0.839 \\
\hline & $n=1,188$ & $n=1,030$ & $n=601$ & $n=492$ & $n=1,789$ & $n=1,522$ \\
\hline \multirow[t]{2}{*}{ Life outlook subscale } & 0.786 & 0.846 & 0.781 & 0.853 & 0.791 & 0.854 \\
\hline & $n=979$ & $n=876$ & $n=501$ & $n=403$ & $n=1,480$ & $n=1,279$ \\
\hline \multirow[t]{2}{*}{ Relationships subscale } & 0.751 & 0.775 & 0.754 & 0.790 & 0.752 & 0.779 \\
\hline & $n=1,190$ & $n=1,028$ & $n=601$ & $n=492$ & $n=1,791$ & $n=1,520$ \\
\hline \multirow[t]{2}{*}{ Total score } & 0.893 & 0.939 & 0.901 & 0.946 & 0.894 & 0.941 \\
\hline & $n=950$ & $n=852$ & $n=498$ & $n=399$ & $n=1,448$ & $n=1,251$ \\
\hline
\end{tabular}

European countries include: Austria, Belgium, Denmark, Finland, France, Germany, Italy, the Netherlands, Portugal, Spain, Sweden, Switzerland, and the UK

$A A Q o L$ adult attention-deficit/hyperactivity disorder quality-of-life, EC European countries, $n$ number of patients, US United States

GEC Index score. Correlations between all AAQoL subscale scores and the BRIEF-A Behavioral Regulation Index score were low-moderate to moderate in European and US patient groups (Supplemental Table 1). Overall, correlations between AAQoL subscale scores and comparator scale scores were very similar in European and US patient groups.

\section{Discriminant validity}

Overall, discriminant validity (measured with analysis of variance) was very similar between European and US groups, with comparable mean AAQoL scores for patient groups with identical CGI-ADHD-S scores. Mean AAQoL total scores decreased with increasing CGI-ADHD-S scores in European and US patients, indicating lower QoL in patients with higher ADHD symptom severity. Furthermore, analyses revealed significant ( $P \leq 0.0001$ for European and US patient groups) differences in mean AAQoL total scores at week 12 between patients with a CGI-ADHD-S score of 1 versus patients with CGI-ADHD-S scores of 2 through 5, indicating discriminant validity of the AAQoL (Fig. 1; too few patients had CGIADHD-S scores $>5$ at week 12 for statistically meaningful analyses).

\section{Responsiveness}

The AAQoL total and subscale scores showed significant (Wilcoxon signed-rank tests, $P<0.001$ ) mean changes from baseline to week 12 in European and US patient groups, indicating good responsiveness.

Mean AAQoL total and subscale score changes were similar between European and US patient groups. Additionally, SRMs were comparable between European and

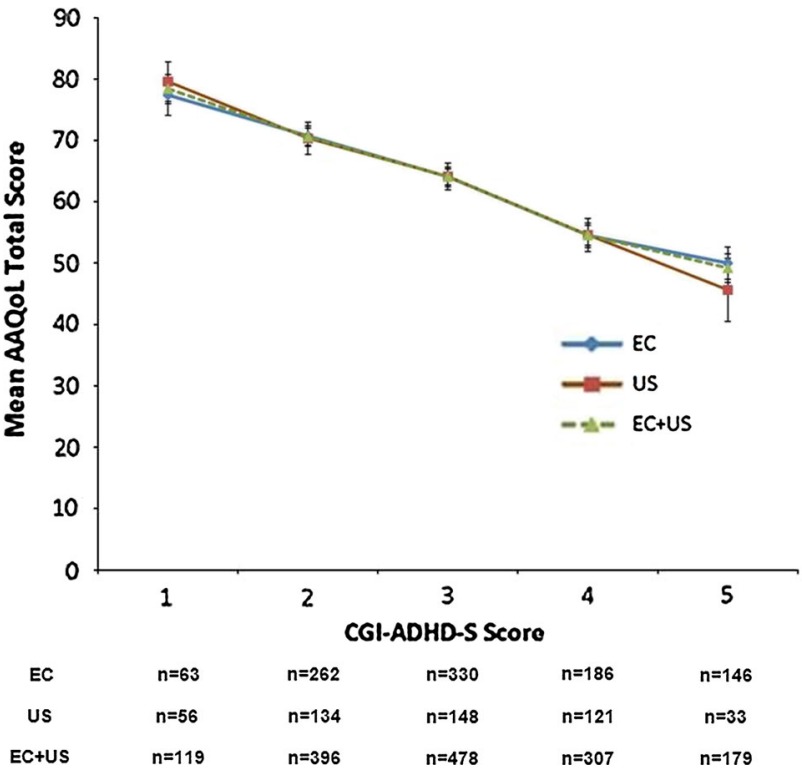

Fig. 1 Comparison of AAQoL total scores and CGI-ADHD-S scores at week 12. AAQoL adult attention-deficit/hyperactivity disorder quality-of-life, $C G I-A D H D-S$ clinical global impression attentiondeficit/hyperactivity disorder-severity, EC European countries, $n$ number of subjects, US United States

US patient groups (Table 4), indicating similar responsiveness in European and US patient groups.

\section{Discussion}

The analyses presented here provide evidence that the AAQoL is a valid measure of ADHD-related QoL in adult European patients. While the AAQoL has previously been validated in US patients, this is the first validation of the 


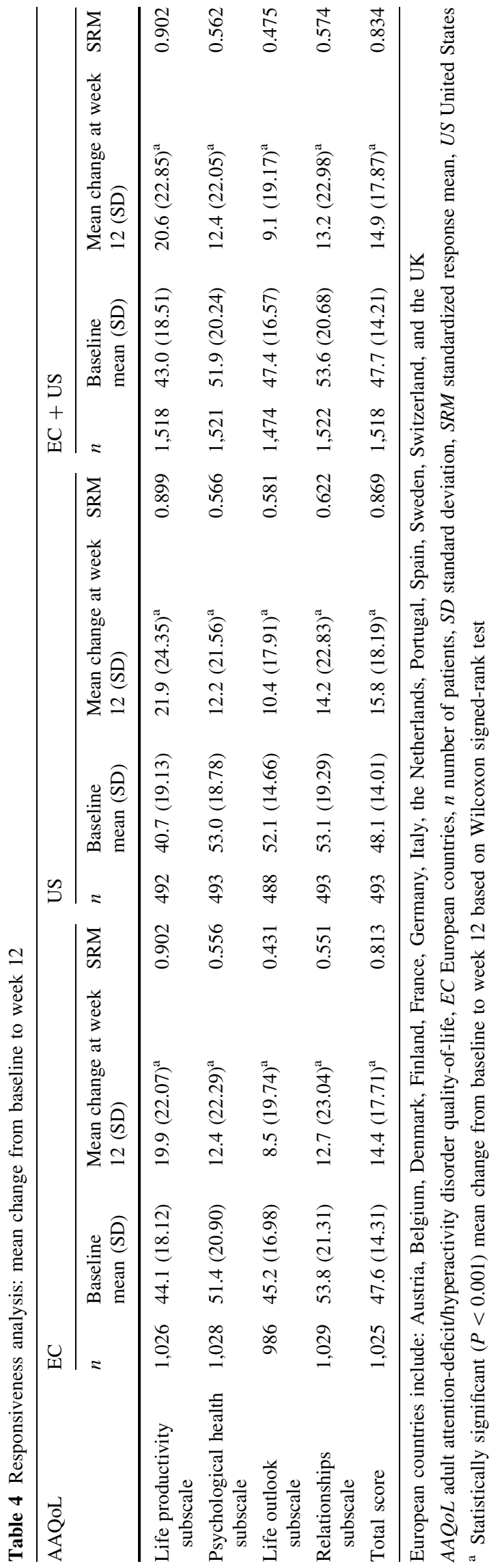

AAQoL in European patients. Although this clinical trial was not designed to test the validity of the AAQoL, it allowed a comparative validation of the scale in one subpopulation (European patients) versus another subpopulation (US patients) in which the AAQoL had been previously validated. Overall, results of all measures for internal consistency, convergent and discriminant validity, and responsiveness were very similar between regions within our study, as well as between our study populations and a prior validation of the AAQoL (Brod et al. 2006).

The exploratory factor analysis confirmed the valid discrimination of four AAQoL subscales in European and US patient groups, with similar loading values for all items in European and US patients. With the exception of item \#29 (your intimate relationship is going well emotionally), the previously published (Brod et al. 2006) factor structure was confirmed in European and US patients. Item \#29 loaded for European and US patients on the AAQoL Relationships subscale; previously, it has been reported to belong to the AAQoL Life Outlook subscale. While it is not surprising that item \#29 originally loaded on the Life Outlook subscale, as it refers to a positive perspective in the patient's life, it is also not surprising that it could load on the Relationships subscale, as it specifically refers to the quality of the patient's relationship. Conceptually, item \#29 could be in either Life Outlook or Relationships subscales.

The AAQoL demonstrated acceptable internal consistency at both baseline and week 12 with Cronbach's $\alpha$ values of $>0.70$ for total and subscale scores in European and US patient populations, which is consistent with prior findings (Brod et al. 2006).

Convergent validity of the AAQoL total score at week 12 was weak to moderate with the CAARS-Inv:SV total ADHD symptom score and the CGI-ADHD-S score and was moderate to strong with the BRIEF-A GEC Index score. These findings are consistent with the fact that the AAQoL was created to specifically address the impact of ADHD symptoms on the life of patients, and some of its questions overlap with questions targeting ADHD symptoms or impairment caused by ADHD in the patients. The moderate-to-strong correlation between the AAQoL and the BRIEF-A GEC Index is also not surprising, as deficits in executive functioning have been demonstrated to be an essential abnormality in ADHD (Coghill 2010). Moreover, it is expected that deficits in executive functioning, which are impairments that the individual has on planning, organizing, and executing practical tasks in life would be associated with a worse perception of QoL.

As expected, all correlation values between AAQoL and comparator scale scores were negative due to the scale definitions: A higher score on the AAQoL indicates better life functioning, while lower scores on the comparator scales indicate a decreased presence of symptoms. 
Discriminant validity was assessed by measuring the ability of the AAQoL to discriminate among patients grouped by their week 12 CGI-ADHD-S scores, because no scale that would be suitable for the assessment of discriminant validity was included in the clinical trial. Therefore, we chose to address discriminant validity as the ability of the AAQoL to discriminate between different levels of ADHD severity. For European and US patients, mean AAQoL scores were significantly different between patients with a CGI-ADHD-S score of 1 , indicating mentally normal, versus patients with CGI-ADHD-S scores of $2-5$, indicating borderline mentally ill up to markedly ill. This suggests that the AAQoL was able to discriminate groups of patients with different disease severity. Overall, results for discriminant validity were very similar between European and US patient groups.

These findings suggest that the AAQoL is a valuable tool to assess treatment effects in clinical trials, addressing an important need in the field. Within the ADHD research community, an increasing demand to incorporate assessments of treatment effects that go beyond pure symptomatic amelioration is being recognized (Coghill 2010). Poor QoL has been identified as an important dimension to be evaluated when assessing treatment effects in clinical trials. The similar responsiveness in European and US patient groups suggests that the AAQoL is an adequate tool for evaluating treatment effects in both geographic regions. While the tool is primarily used in clinical trials, it might also be useful for clinical practitioners when assessing treatment success in their adult patients.

Overall, the moderate correlation between the AAQOL and the CAARS-Inv:SV supports the idea that the 18-item total ADHD symptom score listed in the Diagnostic and Statistical Manual of Mental Disorders (DSM) does not capture the full impact of ADHD on QoL. Consequently, QoL assessment at baseline and during treatment is of much importance. Both DSM symptoms and QoL should be assessed to demonstrate improvement in patients with ADHD, as expressed in the European Medical Agency (EMA) guidelines for drug development in ADHD.

The interpretation of the results of the current study is limited by the open-label study design. Because this study was not designed for a priori investigation of psychometric properties of the AAQoL in a European population, the scales that were chosen as comparators for convergent and discriminant validity were not the standard scales that could be used for that purpose. However, psychometric findings in European and US patient populations in this study were overall very consistent. Together with the prior validation study of the AAQoL in a US population (Brod et al. 2006), the current results suggest that the AAQoL can be used as an adequate measure of QoL in European and US patients. Strengths of the study are the use of a patient population which well represents diverse European regions and the inclusion of a US population in which the AAQoL has previously been validated.

\section{Conclusions}

The AAQoL shows comparable validity in European and US patients, $\geq 18$ to $\leq 50$ years old, for assessing baseline and changes in QoL in adults with ADHD during treatment with atomoxetine. Based on our results, the AAQoL can be a valuable tool to investigate QoL in European adult patients with ADHD and can be used to measure changes in the QoL with treatment in these patients.

Acknowledgments This study was sponsored by Eli Lilly and Company. Eli Lilly and Company contracted inVentiv Health Clinical for statistical, writing, and editorial services for the preparation of this manuscript and approved submission to the journal. MB is a consultant for Eli Lilly and Company, the President of The Brod Group, which provides consulting services to the pharmaceutical industry, and she receives consulting fees for use of the AAQoL. LAA is a consultant for Alcobra Pharmaceuticals, Otsuka Pharmaceuticals, Shire Pharmaceuticals, Theravance, and Major League Baseball; he is on the advisory boards of Alcobra Pharmaceuticals, Otsuka Pharmaceuticals, and Shire Pharmaceuticals; he received research support from the National Institute on Drug Abuse, Eli Lilly and Company, Bristol Myers Squibb, Shire Pharmaceuticals, Chelsea Therapeutics, and Theravance; and he receives royalty payments from New York University for a license of adult attention-deficit/hyperactivity disorder (ADHD) scales and training materials. SL and ANH are full-time employees of inVentiv Health Clinical, LLC, which was contracted by Eli Lilly and Company for statistical, writing, and editorial services for this manuscript. YT and HU are full-time employees and stockholders of Eli Lilly and Company. The authors thank Dr. Fabiano G. Nery, with Eli Lilly and Company during the writing of this manuscript, for intellectual contribution to the study design and critical review of the manuscript. The authors also thank Ms. Vidhya Palaniswamy and Ms. Angela Lorio, both with inVentiv Health Clinical, LLC, for their support in writing and editing this manuscript.

Ethical standards The protocol was reviewed and approved by the appropriate institutional review boards. The study was conducted in conformity with the US Food and Drug Administration Code of Federal Regulations (21 CFR, Part 50), and the Declaration of Helsinki and its amendments. Study procedures and execution were consistent with good clinical practice guidelines and all applicable regulatory requirements. All patients provided written informed consent before undergoing any study procedures.

Open Access This article is distributed under the terms of the Creative Commons Attribution License which permits any use, distribution, and reproduction in any medium, provided the original author(s) and the source are credited.

\section{References}

Adler LA, Spencer TJ, Levine LR, Ramsey JL, Tamura R, Kelsey D, Ball SG, Allen AJ, Biederman J (2008) Functional outcomes in 
the treatment of adults with ADHD. J Atten Disord 11:720-727. doi:10.1097/JCP.0b013e31827d8a23

Adler LA, Liebowitz M, Kronenberger W, Qiao M, Rubin R, Hollandbeck M, Deldar A, Schuh K, Durell T (2009) Atomoxetine treatment in adults with attention-deficit/hyperactivity disorder and comorbid social anxiety disorder. Depress Anxiety 26:212-221. doi:10.1002/da.20549

Biederman J, Faraone SV, Spencer TJ, Mick E, Monuteaux MC, Aleardi M (2006a) Functional impairments in adults with selfreports of diagnosed ADHD: a controlled study of 1001 adults in the community. J Clin Psychiatry 67:524-540

Biederman J, Petty C, Fried R, Fontanella J, Doyle AE, Seidman LJ, Faraone SV (2006b) Impact of psychometrically defined deficits of executive functioning in adults with attention deficit hyperactivity disorder. Am J Psychiatry 163:1730-1738

Bland JM, Altman DG (1997) Statistics notes: Cronbach's alpha. BMJ 314:572. doi:10.1136/bmj.314.7080.572

Brod M, Johnston J, Able S, Swindle R (2006) Validation of the adult attention-deficit/hyperactivity disorder quality-of-life Scale (AAQoL): a disease-specific quality-of-life measure. Qual Life Res 15:117-129

Coghill D (2010) The impact of medications on quality of life in attention-deficit hyperactivity disorder: a systematic review. CNS Drugs 24:843-866. doi:10.2165/11537450-00000000000000

Conners CK, Erhardt D, Sparrow E (1999) Conners' adult ADHD rating scales (CAARS). Multi-Health Systems, Inc, New York

Cronbach LJ (1951) Coefficient alpha and the internal structure of tests. Psychometrika 16:297-334

Danckaerts M, Sonuga-Barke EJ, Banaschewski T, Buitelaar J, Döpfner M, Hollis C, Santosh P, Rothenberger A, Sergeant J, Steinhausen HC, Taylor E, Zuddas A, Coghill D (2010) The quality of life of children with attention deficit/hyperactivity disorder: a systematic review. Eur Child Adolesc Psychiatry 19:83-105. doi:10.1007/s00787-009-0046-3

Food and Drug Administration. Guidance for industry: patientreported outcome measures: use in medical product development to support labeling claims. http://www.fda.gov/downloads/ Drugs/GuidanceComplianceRegulatoryInformation/Guidances/ UCM193282.pdf. Accessed 04 April 2014

Guy W (1976) ECDEU assessment manual for psychopharmacology revised. US Department of Health, Education, and Welfare, Bethesda

HCP Team. Adult ADHD quality of life measure: development, description, and uses. http://www.hcplive.com/publications/DIA LOGS-ADHD/2007/Jun2007/Dialogs_ADHD_Quality_of_Life. Accessed 04 April 2014

Lohr KN, Aaronson NK, Alonso J, Burnam MA, Patrick DL, Perrin EB, Roberts JS (1996) Evaluating quality-of-life and health status instruments: development of scientific review criteria. Clin Ther 18:979-992

Mattos P, Segenreich D, Dias GM, Saboya E, Coutinho G, Brod M (2011) Semantic validation of the Portuguese version of the adult attention-deficit disorder/hyperactivity disorder (ADHD) Quality of Life Questionnaire (AAQoL). Rev Psiquiatr Clín 38:87-90

Mattos P, Louzã MR, Palmini AL, de Oliveira IR, Rocha FL (2012) A multicenter, open-label trial to evaluate the quality of life in adults with ADHD treated with long-acting methylphenidate (OROS MPH): Concerta Quality of Life (CONQoL) Study. J Atten Disord 17:444-448. doi:10.1177/1087054711434772

Matza LS, Johnston JA, Faries DE, Malley KG, Brod M (2007) Responsiveness of the adult attention-deficit/hyperactivity disorder quality of life scale (AAQoL). Qual Life Res 16:15111520

Matza LS, Van Brunt DL, Cates C, Murray LT (2011) Test-retest reliability of two patient-report measures for use in adults with ADHD. J Atten Disord 15:557-563. doi:10.1177/108705471037 2488

National Institute of Mental Health (1985) Clinical global impression scale. Psychopharmacol Bull 21:839-943

Reid R (1995) Assessment of ADHD with culturally different groups: the use of behavioral rating scales. School Psychol Rev 24:537560

Roth RM, Isquith PK, Gioia GA (2005) Behavior rating inventory of executive function-adult version. Psychological Assessment Resources Inc, LutzFL

Stratford PW, Binkley FM, Riddle DL (1996) Health status measures: strategies and analytic methods for assessing change scores. Phys Ther 76:1109-1123

Upadhyaya H, Adler LA, Casas M, Kutzelnigg A, Williams D, Tanaka Y, Arsenault J, Escobar R, Allen AJ (2013a) Baseline characteristics of European and non-European adult patients with attention deficit hyperactivity disorder participating in a placebocontrolled, randomized treatment study with atomoxetine. Child Adolesc Psychiatry Ment Health 7:14. doi:10.1186/1753-2000-714

Upadhyaya H, Ramos-Quiroga JA, Adler LA, Williams D, Tanaka Y, Lane JR (2013b) Maintenance of response after open-label treatment with atomoxetine hydrochloride in international European and non-European adult outpatients with attentiondeficit/hyperactivity disorder: a placebo-controlled, randomised withdrawal study. Eur J Psychiatr 27:185-205

Zhang S, Faries DE, Vowles M, Michelson D (2005) ADHD Rating Scale IV: psychometric properties from a multinational study as a clinician-administered instrument. Int J Methods Psychiatr Res 14:186-201 